\title{
O VÍRUS PROTESTANTE E A AÇÃO PROFILÁTICA DE UM BISPO DE GOIÁS
}

\author{
The Protestant virus and the prophylactic \\ action of a Bishop from Goiás
}

Eduardo Gusmão de Quadros*

\begin{abstract}
RESUMO
No ano de 1918, o bispo de Goiás, D. Prudêncio Gomes da Silva, publicou a carta pastoral "Sobre o protestantismo". Alguns anos antes, um casal de missionários ingleses havia se estabelecido na capital do Estado e fundou a primeira Igreja Cristã Evangélica. Neste artigo, analisaremos o conjunto de representações, valores e estratégias invocados naquela carta para o combate ao protestantismo. Veremos as apropriações feitas, muitas delas a partir do debate teológico europeu, e demonstraremos que há pontos em comum entre o catolicismo romanizado e a pregação protestante.
\end{abstract}

Palavras-chave: catolicismo; conflito religioso; protestantismo; Goiás.

\begin{abstract}
In 1918, the Bishop of Goiás D. Prudêncio Gomes da Silva published the pastoral letter "On the Protestantism". Some years before, a couple of English missionaries had settled in State capital and founded the first Evangelical Christian Church. In this article, I will review the set of beliefs, values and strategies put forward to fight against Protestant presence. I will also see the appropriations drawn mainly from the theological European debate, and demonstrate that there are points in common between romanized Catholicism and the Protestant preaching.
\end{abstract}

Key-words: Catholicism; religious conflict; Protestantism; Goiás.

da Universidade Estadual de Goiás. 
1. Para autores como Pierre Bourdieu, o bonito discurso da igreja sobre o "amor ao próximo" não é muito convincente. Essa mensagem não pode ser totalmente rejeitada, pois está inserida no conjunto de trocas simbólicas que regem a sociedade, contudo, ela está submetida ao imperativo do conflito. O campo religioso, afirma o autor, "deriva sua estrutura, o que é tão evidente no caso da religião, da aplicação sistemática de um único e mesmo princípio de divisão e, assim, só pode organizar o mundo natural e social recortando nele classes antagônicas [...]"'. O antagonismo da sociedade, portanto, torna-se inserido nas representações religiosas, levando-as tendencialmente para o campo da política, para a "diferenciação social e legitimação das diferenças"

Apesar da ênfase dada pelo famoso sociólogo francês, podemos inverter um pouco seu raciocínio e considerar, ao menos como hipótese, que a religião pode fornecer bases para as relações sociais. Scott Mainwaring, partindo de Weber, defende inclusive que "uma igreja poderá renunciar benefícios financeiros, prestígio, expansão institucional e a outros interesses se sentir que sua missão religiosa a obriga agir dessa maneira"3. Ou seja, a esfera religiosa possui regras próprias, uma lógica específica, reprodutora ou não dos conflitos sociais. A fraternidade ensinada, às vezes, pode superar as diferenças, questionando-as ao invés de sempre legitimá-las.

Nesse artigo, não precisamos fechar, a princípio, com nenhuma dessas duas perspectivas. O princípio do conflito é evidente, pois analisaremos uma carta pastoral escrita contra o protestantismo. O documento apresenta uma política de combate e essa postura, anterior à sua redação, está moldando o conteúdo apresentado. As informações históricas e teológicas, independente de sua "verdade", tornam-se armas que destruiriam o inimigo. Essa, inclusive, é a razão de ser do documento. Por outro lado, o que move a pena episcopal é o amor, em primeiro lugar pelo seu rebanho $\mathrm{e}$, em segundo, pelas almas que a heresia protestante estava retirando do aprisco do Senhor. Defender a verdade, desse ponto de vista, sim, é um ato de misericórdia e justiça (o famoso lema do Tribunal do Santo Ofício).

1 BOURDIEU, Pierre. A economia das trocas simbólicas. São Paulo: Perspectiva, 1973, p.

30.

2 Idem, p. 31.

3 MAINWARING, Scott. Igreja católica e política no Brasil. São Paulo: Brasiliense, 1989, p. 24 . 
Não é só uma questão de competição ou o medo de perder fiéis, trata-se de ensinar com clareza a doutrina da igreja, de cumprir sua sagrada missão.

Entendemos que a carta pastoral expressa mais que um combate doutrinário, portanto. Ela expressa um modo de significar o mundo que apresenta duas cosmovisões em conflito. Trata-se de um imaginário no sentido que Castoriadis o definia: um conjunto de significações que institui o real ${ }^{4}$. Para as significações possuírem tal poder, certamente, elas devem ser envoltas por crenças, mesmo que aquele autor não destaque este aspecto. Para nosso estudo, isso é importante, pois na esfera religiosa crer e saber costumam andar de mãos dadas. O discurso pastoral expressa tal saber, articulado logicamente a partir das crenças.

Outro ponto relevante está na interface entre representação, imaginação e real que o conceito de imaginário promove. Assim, veremos que fantasmas do "velho mundo" foram transportados para o interior dos sertões do Brasil. O inimigo construído discursivamente envolve afetos que redimensionam a luta, geralmente engrandecendo o empenho do desafiante.

2. A preocupação com a presença de outras confissões cristãs não era nova no ministério de D. Prudêncio Gomes da Silva. Desde que fora ordenado bispo da Diocese de Goiás, em 1908, ele pedira para que os sacerdotes prestassem atenção na presença de missionários evangélicos ${ }^{5} \mathrm{e}$ de Bíblias protestantes ${ }^{6}$. Em relação a estas últimas, o bispo fez de próprio punho um artigo no jornal diocesano que criou $O$ Lidador, alertando contra as "fraudes" que elas contêm". Depois, na quarta Pastoral, publicada em 1913, ele enviou uma enquete aos padres, perguntando: "Se há acatólicos nessa freguesia, quantos e de quais seitas; [...] se praticam aí o espiritismo; se entram livros, revistas e jornais acatólicos, ímpios ou obscenos [...]"8.

4 CASTORIADIS, Cornelius. Encruzilhadas do labirinto. v. 1. Rio de Janeiro: Paz e Terra, 1986.

5 Utilizamos o termo evangélico como sinônimo dos grupos que advêm historicamente e teologicamente dos movimentos de reforma do cristianismo durante o século XVI, denominados igualmente de protestantes. Não seria o lugar aqui de discutir esse conceito, já tendo sido feito por outros autores. Cf. MENDONÇA, A. G.; VELASQUEZ, P. Introdução ao protestantismo no Brasil. São Paulo: Loyola, 1991.

6 SILVA, D. Prudêncio Gomes. Carta Pastoral saudando os seus diocesanos. São Paulo: Centro de Propaganda Católica, 1908.

7 O Lidador, 1 de janeiro de 1909, p. 2. Este jornal foi publicado inicialmente em Minas, quando Prudêncio ainda era padre, e depois transferido para Goiás.

8 SILVA, D. Prudêncio Gomes. Carta Pastoral anunciando a sua próxima viagem a Roma. Goiás: Typographia Diocesana, 1913. 
Infelizmente, não conseguimos mais encontrar os dados gerados pelo cuidado inquiridor de sua eminência, mas podemos notar o cuidado com a infiltração de identidades religiosas estranhas ao espaço que administrava.

O contato com o protestantismo deve ter ocorrido há tempos em Minas Gerais, onde nasceu, foi ordenado e exerceu os primeiros anos de sacerdócio. Era exatamente daquela região que vinham os missionários evangélicos para Goiás, muitas vezes estrangeiros, vendendo suas "bíblias protestantes" e livros esclarecendo suas crenças doutrinárias". Essa literatura indicava uma relação diferente com o texto, com a escritura para ser mais exato $^{10}$, da que existia no mundo sertanejo. A princípio, a presença de livros não alteraria tanto o catolicismo rural, predominantemente transmitido pela tradição e pelos costumes. Isso indica que a preocupação principal de D. Prudêncio é com aqueles que a igreja buscava reaproximar após a separação com o Estado, em 1890.

O primeiro missionário evangélico que identificamos nas terras goianas morou muito tempo no triângulo mineiro, mantido por missões presbiterianas. Dali o Rev. Boyle fazia incursões periódicas ao sul de Goiás. Em 1888, esteve alguns dias na capital do Estado e foi bem acolhido, principalmente devido aos seus bons contatos com a maçonaria ${ }^{11}$. Era governador, então, o igualmente maçom Leopoldo de Bulhões, que tinha diversas rixas com as autoridades eclesiásticas. Devido a esses conflitos, chegou a pregar para boa quantidade de ouvintes no imponente Teatro São Joaquim. Empolgado, o reverendo escreveu em seu diário de viagem: “O

9 O modo de penetração dessa literatura é bem interessante, pois se trata de uma venda inculturada no mundo sertanejo. Os colporters, como são chamados, iam vendendo a literatura evangélica e as bíblias no lombo das mulas, como faziam as demais tropas comerciais da região. Eles eram "o braço direito" do trabalho missionário (cf. FERREIRA, Julio. História da Igreja Presbiteriana no Brasil. São Paulo: Casa Publicadora Presbiteriana, 1959, p. 181). O catolicismo exerceu um forte combate contra a presença de maçons em suas hostes, sendo a maçonaria condenada.

10 O conceito de escritura é importante ao estabelecer uma relação entre texto e verdade, seja ela a verdade objetiva da ciência ocidental, seja a religiosa que, entre os evangélicos, depende das sagradas escrituras.

11 Essa relação com a maçonaria não deve assustar os leitores, pois foi uma constante na expansão inicial do protestantismo. Diante de alguma dificuldade, o Reverendo Boyle costumava perguntar: "Não há algum maçom na cidade?" (apud FERREIRA, Julio. História da Igreja Presbiteriana no Brasil. São Paulo: Casa Publicadora Presbiteriana, 1959, p. 179). O catolicismo exerceu um forte combate contra a presença de maçons em suas hostes, sendo a maçonaria condenada como herética pelo papa Leão XIII, entre outros. 
Brasil está cheio de protestantes". Só faltam "professar sua fé, [que] poderíamos organizar igrejas evangélicas" ${ }^{\prime 2}$.

Essa suposta "tendência" ao protestantismo devia-se à carência de padres, a certa independência religiosa em relação à hierarquia e à curiosidade que os estrangeiros geravam. Além disso, os americanos e ingleses representavam a "civilização", o progresso e a modernidade, seja para a elite instruída, seja para a população mais simples. Eram, destarte, admirados, apesar dos padres alertarem contra eles. A pastoral coletiva de 1910, documento que serviu de regimento para a igreja daquele período, classificava como "pecado mortal" qualquer contato com os protestantes e com sua literatura ${ }^{13}$.

Outro missionário passou vários meses na capital goiana, apesar de não ter fixado residência ali. Nos idos de 1905, o médico inglês Frederick Glass batizou algumas pessoas da cidade, destacando-se um preso que mais tarde tornou-se diácono da Igreja Cristã Evangélica. Esta igreja foi fundada em 1911 e tinha como pastor o também médico inglês Archibald Mctyre. É contra sua atividade que D. Prudêncio parece mirar mais especificamente na sua carta pastoral.

3. Há outro fato importante também naquela época. O caso foi inclusive citado no texto da pastoral: um padre da Diocese teria passado para o lado protestante. A princípio, pensamos ser o promissor sacerdote Victor Coelho de Almeida. Ele foi um importante intelectual goiano, membro da Academia de Letras, deixou a batina e sua "conversão" foi bastante alardeada na época. Verificando seus dados biográficos, porém, conferimos que ele deixou a igreja católica em 1913, mas só aderiu ao protestantismo em 1919, depois da redação do documento em estudo ${ }^{14}$. Trata-se de um padre estrangeiro $^{15}$, então, talvez seja o espanhol Ricardo Mayorga. Ele trabalhava

12 A obra de Boanerges Ribeiro, Protestantismo e cultura brasileira (São Paulo: Casa Publicadora Presbiteriana, 1981) transcreve diversos trechos desse diário, publicado originalmente em 1899 no jornal norte-americano The Missionary.

13 Esse documento foi publicado em diversas partes pelo jornal O Lidador. O trecho acerca do protestantismo encontra-se na edição do dia 09 de novembro de 1911, p. 1.

14 COUTINHO, Sérgio Ricardo. O ex-padre: a trajetória política e religiosa de Victor Coelho de Almeida (1879-1944). Brasília: Editora Ser, 1999. p. 128 e 134.

15 SILVA, D. Prudêncio Gomes. Carta Pastoral sobre o Protestantismo. Goiás: Typographia Diocesana, 1918, p. 3. 
na paróquia de Catalão e, conforme as memórias de um missionário, foi perseguido após cambiar de instituição religiosa ${ }^{16}$. Não temos a data exata desse acontecimento, mas, pelo relato, ocorreu durante a Primeira Guerra Mundial, coincidindo com o período de redação da Carta Pastoral.

De qualquer modo, esses casos parecem ter sido relativamente comuns, havendo uma grande propaganda a respeito. O considerado "primeiro pastor brasileiro", inclusive, tinha sido sacerdote católico da diocese de São Paulo. Depois de José Manuel da Conceição aderir à igreja presbiteriana, ele voltou à região em que trabalhava para ensinar suas novas crenças religiosas e arregimentar prosélitos ${ }^{17}$. Os batistas e os metodistas, igualmente, tiveram seus "ex-padres".

A existência dessas "conversões" auxiliava a difusão da mensagem evangélica. Conforme os dados apresentados pelo bispo, havia quatro ou cinco paróquias com presença evangélica em 1907 e dez anos depois cerca de 14 paróquias já estavam infeccionadas com o "vírus do protestantismo"18. Conforme os dados de Ordália Araújo, as paróquias "infectadas" eram as da região sudeste do Estado, próximas ao triângulo mineiro ${ }^{19}$.

A linguagem médica utilizada ${ }^{20}$ pelo bispo demonstra seu ofício de curador das almas. Salvação e saúde possuem a mesma raiz etimológica, estando intimamente relacionadas na teologia clássica. Muito se fala da dicotomia entre corpo e alma do cristianismo, mas eles permanecem relacionados, pois o pecado causaria doenças e os sacramentos trariam a cura em ambos os "níveis". Por sinal, tal relação tornou-se mais acentuada durante o século XIX, afirma Alain Corbin ${ }^{21}$.

16 TIPPLE, Archibald. Bandeirantes da Bíblia no Brasil Central. Goiânia: Casa Editora Aplic, 1972, p. 48.

17 SOUZA, Silas de. José Manoel da Conceição: o padre-pastor protestante. Rio de Janeiro: Novos Diálogos, 2011.

18 SILVA, D. Prudêncio Gomes. Carta Pastoral sobre o Protestantismo. Goiás: Typographia Diocesana, 1918, p. 2.

19 Ela cita a criação da Igreja Presbiteriana no município de Santa Luzia em 1983, a Igreja Cristã Evangélica em Catalão, do ano de 1902, e a Igreja Batista na mesma cidade seria de 1905. ARAÚJO, Ordália C. Entre o real e o ideal: a tentativa de protestantização do campo religioso goiano. In: SERPA, E.; MAGALHÃES, S. (Orgs.). Histórias de Goiás: memória e poder. Goiânia: Editora da UCG, 2008, p. 109. Essas igrejas muitas vezes não tiveram continuidade, mas havia grupos de evangélicos morando nessas cidades por onde passavam os missionários.

20 Na quarta Carta pastoral, de 1915, D. Prudêncio já alertava quanto ao perigo do "contágio com escritos e reuniões que tratem dos interesses da seita, ainda que por simples curiosidade e distração" (SILVA, 1915, p. 39; grifo nosso). Trata-se de uma citação da Pastoral Coletiva de 1910.

21 CORBIN, Alain. História do corpo. v. 2. Rio de Janeiro: Petrópolis, 2008, p. 60. 
Mas essa ideia de um vírus protestante também remete à ideia de invasão perniciosa e de um crescimento sem razão ou lógica. D. Prudêncio não vê como aquele mal e seu conjunto de erros poderiam prosperar. Pelo espírito de Deus não podia ser, restando a alternativa das forças malignas. Não o diz claramente, é verdade, falando apenas do "espírito de rebelião", ou seja, semelhante ao de Lúcifer, que guiaria os reformados desde Lutero 22 .

Foi dessa forma que ele iniciou o combate ao mal: com uma argumentação histórica.

4. Seu intuito era demonstrar o que seria verdadeiramente o mundo protestante. Traça, então, um quadro histórico, falando dos fundadores do movimento na Europa. Sua concepção historiográfica é providencialista, com Deus guiando os acontecimentos. Inspira-se - citando diversas vezes - a obra do colega de mitra, o francês Jean Bossuet ${ }^{23}$. Ela é a principal fonte utilizada para descrever os principais personagens do protestantismo: Lutero, Melanchton, Zwinglio, Calvino, até Henrique VIII.

Destarte, ele faz dos dados históricos uma plataforma político-religiosa. Narra com fidelidade os principais fatos, sempre expressando sua visão através dos adjetivos. A redação não pretende ser científica ou objetiva simplesmente, mas guiar com juízos de valor verdadeiros. Essa característica relaciona-se à cosmovisão de $\mathrm{D}$. Prudêncio, sua posição enquanto ministro de Deus perante a sociedade. Ele precisa defender a mensagem correta para a humanidade, e apontar os erros enganadores para seu rebanho.

Assome-se a existência de diversas comparações, implícitas ou explícitas, retiradas da teologia cristã. A objetividade ipsis litteris não é propriamente buscada, mas certa cientificidade no trato dos fatos. Já falamos da aproximação entre Lutero e Lúcifer. O orgulho seria o principal traço da personalidade de ambos ${ }^{24}$. Zwinglio, Calvino e os anabatistas, todos, desrespeitam a autoridade e a ordem do que Deus criou. Ao invés

22 SILVA, D. Prudêncio Gomes. Carta Pastoral sobre o Protestantismo. Goiás: Typographia Diocesana, 1918 , p. 5.

23 Geralmente, Bossuet é citado como grande exemplo da concepção de história providencialista. Claro que, nessa visão dos processos históricos, a apologética faz parte da interpretação dos fatos. Cf. BOURDÉ, G.; MARTIN, F. As escolas históricas. Lisboa: Editorial Presença, 1990.

24 SILVA, D. Prudêncio Gomes. Carta Pastoral sobre o Protestantismo. Goiás: Typographia Diocesana, 1918, p. 6. 
de serem lembrados, deveriam ser "uma vergonha para os protestantes", que até costumam esconder suas origens ${ }^{25}$. Com esse dever da lembrança histórica, portanto, ele traz à luz alguns malfeitores da história da igreja de execranda memória. Não deixa esquecer o que deveria já ter desaparecido, tornando-se somente história... Com tais fundadores, como esses grupos religiosos poderiam pretender ensinar algo de bom? Nessa concepção de história, as origens ruins geram um futuro ainda pior!

Apesar disso, esse "monstro de muitas cabeças" chegou ao Brasil. O bispo demonstra estar bem informado, falando da história da Igreja Evangélica Fluminense, da Igreja Presbiteriana, dos Batistas, dos Episcopais. Inclui ainda, em seu relato, as igrejas surgidas entre os imigrantes (luteranos "para os alemães" e anglicana "para os ingleses"). Sua intenção, contudo, não é ser exaustivo, nem convencer pela erudição. Ao descrever as "cabeças do monstro", ele ressalta a competição entre si, suas divisões internas e enormes divergências. Grupos tão divididos poderiam, afinal, ensinar $a$ verdade?

5. Bem diferente era o catolicismo. Óbvio que, nessa narrativa histórica, a doutrina da Igreja Católica Romana enquanto o verdadeiro lugar da revelação divina estava implícita. Ela possui, afinal, um chefe supremo respeitado e seguido por todos os fiéis. Esse chefe, por sinal, fora completamente desrespeitado por Martinho Lutero, que negou insultuosamente "a infalibilidade do Papa em matéria de fé" ${ }^{26}$. Ora, como se sabe, tal dogma só fora estabelecido realmente no século XIX, nas últimas sessões do Concílio Vaticano I. Por que D. Prudêncio escrevera isso? Teria o bispo cometido um grande anacronismo?

Tal ideia poderia até ser levantada, se não existisse uma concepção eclesiológica por trás. A infalibilidade papal ou ascensão de Maria em corpo em alma poderiam até ser dogmas reconhecidos recentemente, mas, antes de tudo, são verdades eternas. A igreja de Deus não muda, não inventa novas doutrinas, como fazem de maneira contumaz os grupos protestantes. Essa verdade, por sinal, é a base da unidade universal, ou seja, católica, ao contrário das seitas evangélicas, que parecem se multiplicar como células cancerígenas.

25 Idem, p. 7.

26 SILVA, D. Prudêncio Gomes. Carta Pastoral sobre o Protestantismo. Goiás: Typographia Diocesana, 1918, p. 15. 
Sim, o protestantismo adoece todo o corpo social. O bispo de Goiás não acusa o poder dos dólares norte-americanos pelo crescimento, nem relaciona a mensagem evangélica com o imperialismo, como boa parte da literatura polêmica gerada pelo catolicismo da época ${ }^{27}$. Para ele, a doença corrói por dentro, minando os fundamentos da verdade e da união harmônica entre as pessoas.

Ele ressalta bastante, aliás, a divisão como um problema grave. Adentra, por exemplo, nas querelas dogmáticas, abordando a leitura individual da Bíblia, mas a considera um grande empecilho para o conhecimento de Deus. Como poderia um mesmo livro, de um mesmo autor, gerar tantas interpretações diferentes? Um mesmo texto sobre Cristo divide os grupos supostamente evangélicos e em meio a tal confusão o espírito de Deus não pode estar.

Além do que "a leitura e a interpretação individual da Bíblia não são o meio escolhido por Jesus Cristo para conduzir os homens ao conhecimento e à prática de Sua religião"28. D. Prudêncio utiliza das próprias "armas protestantes", ou seja, referências à vida e aos ensinos de Jesus, para legitimar as doutrinas católicas. Há ainda uma referência ao líder maior do protestantismo, Martinho Lutero, para apresentar aos seus leitores as dificuldades do estudo bíblico ${ }^{29}$. Quer virar o feitiço contra o feiticeiro, demonstrar as contradições e a inviabilidade de tais noções.

A "autoridade" das escrituras remete, de fato, ao respeito às autoridades eclesiásticas. Os evangélicos não seguem seus pastores afinal? Seria impossível tal interpretação individual, pois ela é sempre institucional, mesmo que os grupos protestantes não o assumam. Ora, com essa argumentação, ele aproxima o protestantismo do catolicismo, buscando demonstrar que não seriam tão distintos: ambos são autoritários e seguem hierarquias. Tal semelhança retornará na noção de "povo".

Por outro lado, encontramos nessa crítica às igrejas protestantes um ponto nevrálgico da divergência com o catolicismo, ao menos como este é concebido por sua eminência. A noção de pessoa é radicalmente diferente. A trazida pela mensagem protestante está bem mais próxima do individualismo

27 GONÇALVES, Carlos Barros. As polêmicas antiprotestantismo nas primeiras décadas do século XX. Revista Fronteiras, UFGD, v. 12, n. 21, p. 151-179, 2010.

28 SILVA, D. Prudêncio Gomes. Carta Pastoral sobre o Protestantismo. Goiás: Typographia Diocesana, 1918, p. 9.

29 Idem, p. 11. 
moderno, seja observado o ponto de vista econômico (o consumidor), o político (o eleitor), o científico (o inventor) ou o estético (o artista ou o autor). $\mathrm{Na}$ tradição romana, o social tem um peso bem mais forte, compondo o que poderíamos chamar de uma visão corporativista de pessoa. Daí a mensagem colocada no apelo final da Carta Pastoral: "[...] sereis firmes na religião de vossos pais, que é também a vossa, [...] porquanto a religião é uma herança sagrada de que não nos é lícito mudar como se muda de vestes do corpo"30.

A questão da convicção pessoal, básica desde os primórdios da Reforma $^{31}$, não seria, a princípio, tão importante. Mas é claro que na pena episcopal há também um uso político da tradição, um reforço da autoridade do passado diante das possíveis tentações de mudança. Deus é recebido dos pais e não se trata exatamente de uma escolha. Mas se fosse realmente assim, por que a ênfase na firmeza dos fiéis?

6. Isso ocorre porque nem todos são assim, firmes. Aliás, isso é bastante raro, o que é de pleno conhecimento do reverendíssimo pastor. Segundo ele, existem três tipos básicos de católicos. Os primeiros são os "instruídos e convictos", numericamente pouco expressivos e que permanecerão dentro do catolicismo. Os segundos são os de "pouca instrução", chamados também de nominais. Esses caem na indiferença religiosa, uma conseqüência direta dos debates teológicos promovidos pelos reformadores. Prossegue a pena episcopal:

Não continuam católicos porque, não tendo a necessária instrução e boa vontade sobre sua religião, pensarão logo que assiste razão ao protestantismo quanto às acusações que este faz contra nós. Não se tornam protestantes porque entendem não lhes ficar bem mudar de religião [...] Um grande mal, portanto, para o indivíduo e para a família ${ }^{32}$.

Sua distinção "sociológica" atribui justamente ao social a manutenção de uma confissão cristã. A comodidade vence a razão; já a pessoa

$30 \quad$ Idem, p. 19.

31 Bom lembrar que Lutero a afirma como um locus privilegiado diante das duas grandes forças sociais de seu tempo: o Papa e o Imperador. Essa questão da consciência individual, então, tornou-se central, muito mais que a tradição socialmente estabelecida.

32 Idem, p. 16. 
pouco instruída, diz o bispo, considera as críticas dos evangélicos contra o catolicismo corretas. Seria uma a confirmação da ideia de que o protestantismo é muito mais racional, como defende Weber? ${ }^{33}$ De qualquer modo, sem coragem de assumir o que pensa, o indivíduo termina por relegar o nível religioso para o secundário, semelhantemente ao que fez a sociedade moderna.

A indiferença é apontada como o primeiro dos grandes males trazidos pela divergência protestante. $\mathrm{O}$ segundo grande mal atinge diretamente o terceiro tipo de católico: "os simples da roça". Eles "não se tornam protestantes, porém fanáticos da Reforma" 34 . O fanatismo é um comportamento que tende para o desequilíbrio mental, "uma loucura", mas na análise episcopal a transcende, passando a ser um grave "perigo social" 35 . As massas afinal, como afirmava Gustave Le Bon $^{36}$, ao aderirem a uma crença religiosa, tornam-se cegas; incapazes de "discutir seus dogmas, são tomadas pelo desejo de difundi-los e têm a tendência para considerarem inimigos a todos os que não os aceitam".

$\mathrm{Na}$ visão do bispo, indivíduo e sociedade estão intimamente ligados. Mas ele vai além da "sociologia" quando classifica os comportamentos enquanto uma anormalidade, ou seja, uma patologia social. Essa é a marca de uma visão medicinal da sociedade que marcava os intelectuais do início do século $\mathrm{XX}^{37}$. A peculiaridade de D. Prudêncio está em invocar a insanidade não para disciplinar os espaços públicos, mas para o controle do comportamento religioso. O vírus protestante se espalha pelo contato social, especialmente entre os mais simples. Apesar de ser uma religião tão individualista, é o meio que acabaria determinando a forma da fé.

Outro aspecto é sua tipologia utilizando o nível cultural. Aqui, na verdade, o bispo de Goiás se aproxima dos protestantes que combate.

33 WEBER, Max. A ética protestante e o espírito do capitalismo. São Paulo: Companhia das Letras, 2004.

34 SILVA, D. Prudêncio Gomes. Carta Pastoral sobre o Protestantismo. Goiás: Typographia Diocesana, 1918, p. 16.

35 Idem, p. 17.

36 A obra foi publicada em 1895 e suas ideias foram bastante difundidas. A aproximação com Le Bon não significa que D. Prudêncio tenha lido essa obra, mas o aproxima da cosmovisão das teorias sociais que circulavam no Brasil da época. LE BON, Gustave. Psychologie des foules. Paris: Presses Universitaires, 1963.

37 O artigo de Everardo Nunes traz uma boa revisão bibliográfica sobre essa perspectiva de análise do social. NUNES, Everardo D. Sobre a história da saúde pública. Ciências e Saúde Coletiva, Rio de Janeiro, v. 5, n. 2, 2000. 
Desde, ao menos, a romanização do catolicismo ${ }^{38}$ que há uma correlação íntima entre formação, consciência e fé. O fiel é aquele que compreende, que raciocina e não apenas repete, como no antigo catecismo. Tal projeto pedagógico envolve, claro, uma dimensão maior que as simples doutrinas eclesiásticas, buscando transformar a sociedade como um todo.

Por isso, as igrejas católicas e protestantes fazem um grande esforço para educar a população. Sua caracterização como "aqueles que precisam aprender", como objeto a ser transformado é, destarte, compartilhada. Tanto o discurso católico do início da República quanto o evangélico é:

a) conversionista, tentando conquistar para si o que podemos chamar de "povo" e transformar seu comportamento;

b) reformista, em sentido teológico, pois intentava purificar suas práticas rotineiras, geralmente consideradas desviantes;

c) evolucionista, propagando a crença de que seria um dever social da religião contribuir para seu progresso.

7. As aproximações não param por aí. Vimos que na ótica do bispo os convertidos ao protestantismo facilmente se tornam fanáticos. Poderíamos inverter o raciocínio e aplicar essa categoria a sua própria leitura do movimento protestante? Ora, a categoria de fanatismo costuma ter utilização eminentemente política, servindo exatamente para combater o modo do outro pensar e crer.

Sabemos que não é comum aplicar tal categoria aos estudos do catolicismo. $\mathrm{O}$ modelo sociológico de igreja leva à compreensão que ela interage com o mundo envolvente e que o compromisso gerado pela fé não é tão radical. Já as seitas seriam o espaço propício para a postura fanática, pois tais grupos, geralmente minoritários, rejeitam os valores do ambiente em que estão e costumam se considerar como portadores do único caminho da salvação. Na literatura sociológica tradicional, os protestantes são exemplos de seitas e o catolicismo, de igreja ${ }^{39}$.

38 Processo de maior adequação das crenças e práticas católicas às diretrizes advindas de Roma, ocorrido aproximadamente de 1870 a 1930 no Brasil.

39 Ressalte-se que, antes de serem tomados pela perspectiva sociológica, os termos aparecem comumente na literatura polêmica. No jornal diocesano O Lidador, do dia 29 de junho de 1916, por exemplo, as seitas são consideradas o lugar para "as paixões desmedidas". O artigo intitula-se "No Labyrintho do Protestantismo" (p. 3). 
No caso da pastoral em estudo, entretanto, parece que o comportamento típico de seita está no representante máximo da igreja católica de Goiás. Podemos ainda suspeitar que essa divisão conceitual esconde preconceitos socioteológicos perante as minorias identitárias do campo religioso. Mas caberia enquadrar o bispo como um fanático?

Ao termo fanatismo não se deve dar uma definição objetiva. Como aponta o estudo de Alberto Toscano ${ }^{40}$, ele é utilizado em certas situações históricas para rebaixar ao nível irracional um grupo oposto. Dentro dessa historicidade pragmática, enxerga de maneira monolítica tal grupo, colocando como intolerante o que, na verdade, o sujeito rejeita ${ }^{41}$. Não se trata, portanto, de uma leitura das identidades, mas da geração de estereótipos. No caso da pastoral em estudo, esse procedimento é realizado, inclusive, depois de apontar para o grave problema das inúmeras divisões, características do mundo protestante.

Então, D. Prudêncio se coloca do lado da certeza e da verdade, rejeitando quem rejeita sua posição de representante divino e da igreja de Cristo. Curioso que o católico bem instruído, que sabe o que crê e é firme na fé, elogiado anteriormente na carta, corresponde aproximadamente ao "fanático" que combate tenazmente a fé católica por assumir outra identidade religiosa. O outro pode funcionar como espelho de si.

\section{Considerações finais}

O conflito apresentado não deve ser considerado episódico ou superficial, pois é comum que as identidades sejam constituídas no contraste com os outros. Elas criam mecanismos de produção de diferenças, na busca pela continuidade e estabilidade dos vínculos sociais. Com isso, geram um núcleo de representações homogeneizantes, especialmente em relação aos grupos rivais. Nesse sentido, pode-se afirmar que foi a Reforma do século XVI que provocou definições mais claras do que é ser católico.

40 TOSCANO, Alberto. Fanaticism - on the uses of an idea. New York: Verso, 2010.

41 Idem, p. XIII. 
Desde então, o processo vem sendo refeito em várias partes do mundo, com a incorporação de algumas peculiaridades.

O que a descrição do bispo selecionou para combater? A multiplicação dos grupos, as doutrinas enganosas, a "ilusão" do acesso direto à palavra de Deus. Nessas críticas, uma concepção de sociedade estava em jogo, não sendo as doutrinas aspectos pontuais. Nada sobre a influência norte-americana, o imperialismo estrangeiro ou as escolas protestantes, como era comum na literatura polêmica. A relação entre catolicismo e nacionalidade brasileira, comum na época, igualmente não foi invocada.

Ao mesmo tempo, D. Prudêncio não deixou de fazer uma autocrítica ao trabalho de formação católica, basicamente sacramental. Boa parte da população tinha pouca ou nenhuma instrução na fé, o que facilitava a penetração do protestantismo. Assome-se a falta de padres e a vida em desacordo com as normas eclesiásticas, problemas corriqueiros na administração da extensa Diocese de Goiás ${ }^{42}$.

A Carta Pastoral sobre o Protestantismo deveria ser lida e divulgada pelos párocos nas missas, celebrações, festas e desobrigas ${ }^{43}$. Com isso, talvez, o efeito inverso tenha ocorrido, pois o combate episcopal acabava por divulgar a novidade protestante nos mais longínquos sertões. A profilaxia terminou por criar um ambiente propício para que o vírus se multiplicasse.

Recebido em dezembro de 2010. Aprovado em fevereiro de 2011.

42 Em 1916, Goiás tinha somente vinte e quatro padres seculares e vinte e um religiosos para o território que, hoje, engloba os Estados de Goiás e Tocantins. Cf. SILVA, D. Prudêncio Gomes. Carta Pastoral anunciando o desdobramento da Diocese de Goyaz. Goiás: Typographia Diocesana, 1916.

43 SILVA, D. Prudêncio Gomes. Carta Pastoral sobre o Protestantismo. Goiás: Typographia Diocesana, 1918, p. 20. 